\title{
AKAPS Act in a Two-Step Mechanism of Memory Acquisition
}

\author{
Lisa Scheunemann, ${ }^{1}$ Philipp Skroblin, ${ }^{2}$ Christian Hundsrucker, ${ }^{2}$ Enno Klussmann, ${ }^{2}$ Marina Efetova, ${ }^{1}$ \\ and Martin Schwärzel ${ }^{1}$ \\ ${ }^{1}$ Free University Berlin, Biology-Genetics, D-14195 Berlin, Germany and ²Max-Delbrück-Centrum für Molekulare Medizin, 13125 Berlin, Germany
}

Defining the molecular and neuronal basis of associative memories is based upon behavioral preparations that yield high performance due to selection of salient stimuli, strong reinforcement, and repeated conditioning trials. One of those preparations is the Drosophila aversive olfactory conditioning procedure where animals initiate multiple memory components after experience of a single cycle training procedure. Here, we explored the analysis of acquisition dynamics as a means to define memory components and revealed strong correlations between particular chronologies of shock impact and number experienced during the associative training situation and subsequent performance of conditioned avoidance. Analyzing acquisition dynamics in Drosophila memory mutants revealed that rutabaga (rut)-dependent cAMP signals couple in a divergent fashion for support of different memory components. In case of anesthesia-sensitive memory (ASM) we identified a characteristic two-step mechanism that links rut-AC1 to A-kinase anchoring proteins (AKAP)-sequestered protein kinase A at the level of Kenyon cells, a recognized center of olfactory learning within the fly brain. We propose that integration of rut-derived cAMP signals at level of AKAPs might serve as counting register that accounts for the two-step mechanism of ASM acquisition.

\section{Introduction}

Memory is not an entity but rather divisible into particular components, also known as memory phases, which can be categorized by experimental means like amnestic procedures or genetic manipulation (Müller and Pilzecker, 1900; Lechner et al., 1999; McGaugh, 2000; Schwärzel and Müller, 2006). Consequently, the increase in accuracy and durability of memory performance that usually follows prolonged experience can be achieved by at least two different ways: first, through gradual and continuous regulation of one particular component or, second, through the discontinuous activation of additional components. Either of these alternatives appears meaningful from an evolutionary point of view by ensuring that only relevant, i.e., strong and/or repeatedly experienced events, are memorized. However, which molecular and neuronal mechanisms are engaged in regulating the discontinuous acquisition of particular memory components is poorly understood.

Here, we used the Drosophila aversive olfactory conditioning procedure (Tully and Quinn, 1985) to investigate the principal organization of memory acquisition. During the pavlovian training procedure flies associate an olfactory cue-the conditioned

Received March 25, 2013; revised Sept. 26, 2013; accepted Sept. 27, 2013.

Author contributions: E.K. and M.S. designed research; L.S., P.S., and C.H. performed research; L.S., P.S., C.H., E.K., and M.E. analyzed data; L.S. and M.S. wrote the paper.

This work was supported by Deutsche Forschungsgemeinschaft Grant SCHW1410/1-1 and R011-MH-086415-01 to M.S. and grant KI1415/4-2 to E.K. We are thankful to Samuli Holopainen for technical support. Fly stocks were obtained from the Bloomington Stock Center (Blooming, IN).

Correspondence should be addressed to Martin Schwärzel, Free University Berlin, Biology-Genetics, Takustrasse 6, D-14195 Berlin, Germany. E-mail: martin.schwaerzel@fu-berlin.de.

DOI:10.1523/JNEUROSCI.1303-13.2013

Copyright $\odot 2013$ the authors $\quad 0270-6474 / 13 / 3317422-07 \$ 15.00 / 0$ stimulus (CS)—with electric shock reinforcement, i.e., the unconditioned stimulus (US). Given the high level of performance reached in control strains after a single-cycle training procedure (see Fig. 1A), the aversive olfactory learning paradigm had quickly evolved as a "gold standard" and dominated the field of genetic dissection of memory (McGuire et al., 2005). Notably, high performance is due to optimization of two US-related parameters: first, the shock number and, second, the shock impact, i.e., the overall DC voltage applied. Exactly those two parameters were the target of systematic variation to estimate their impact on accuracy and duration of odor memory in the present study. We report that acquisition of genetically defined components, i.e., short-term memory (STM), anesthesia-sensitive memory (ASM), and anesthesia-resistant memory (ARM), are triggered by different experiences made during the commonly used single cycle training procedure, and that those components are separated at level of the molecular signaling events engaged.

\section{Materials and Methods}

Fly care. Flies were raised at $24^{\circ} \mathrm{C}$ and $60 \%$ relative humidity with a $14 / 10$ $\mathrm{h}$ light/dark cycle on cornmeal-based food following the Würzburg receipt (Guo et al., 1996). Genetic crosses were performed according to standard procedures and behavioral experiments were performed with 3 to 5-d-old male F1 progeny of homozygous parental lines. Since mutations where located on the $\mathrm{X}$ chromosome animals where selected for gender after the behavioral test to separate hemizygote male F1 from heterozygote female F1 progenies. Wild-type Canton-S did not show any gender-specific (female vs male) effects on memory performance, i.e., $68.4 \pm 2.5$ versus $67.5 \pm 2.0$ for STM, $44.1 \pm 2.0$ versus $42.6 \pm 1.7$ for mid-term memory (MTM), and $21.4 \pm 1.1$ versus $20.1 \pm 1.4$ for ARM. Genetic lines used in this study were not outcrossed to a reference strain.

Behavioral experiments. Flies to be tested in behavioral experiments were transferred to fresh food vials for up to $48 \mathrm{~h}$ before the test. Behav- 
A

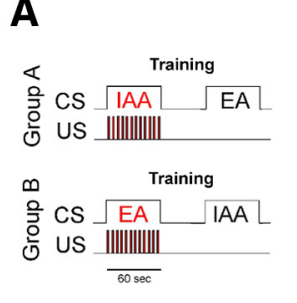

B

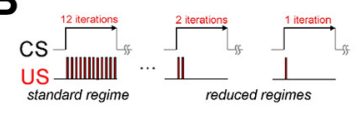

C

Test
IAA
vs
EA
Test
IAA
vs
EA
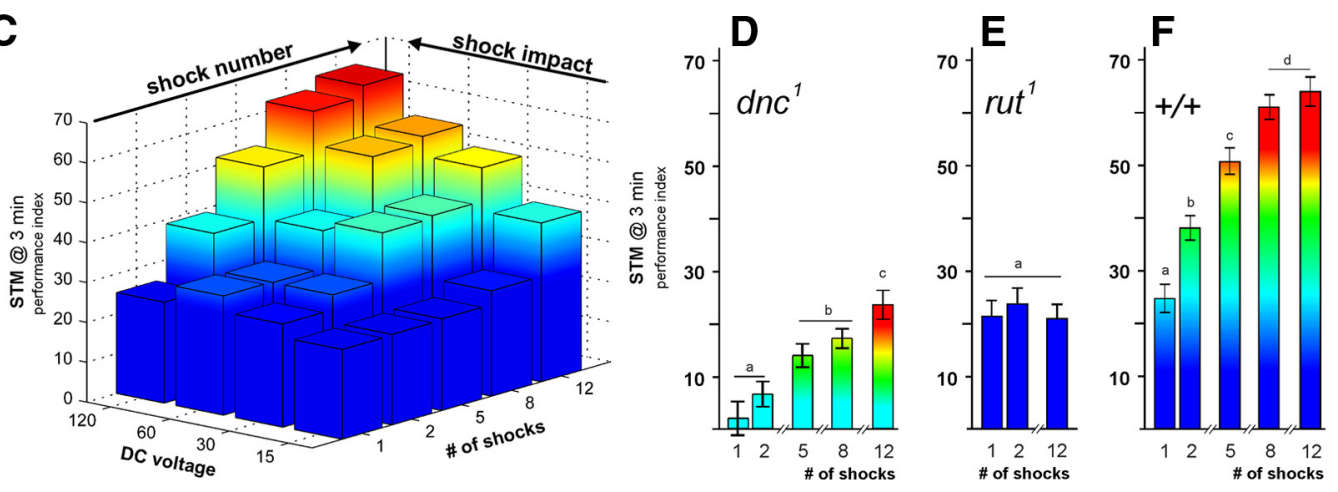

Figure 1. Independent contribution of shock number and intensity to reinforcement. Aversive olfactory conditioning induces associative memories that guide behavior in subsequent test situations and immediately after the training session animals perform due to STM. $\boldsymbol{A}$, In the standard training situation originally introduced by Tully and Quinn (1985) animals are presented one particular odor of an odor pair while experiencing inevitable electric shock punishment that is administered in fast succession, followed by the unpunished control odor. To exclude unspecific odor effects the identity of punished and control odor-in this study IAA and EA-is exchanged in two separate experiments and both groups are tested in a similar situation for odor preference using a forced choice maze. The percentage of correct choice, i.e., avoidance of the formerly punished odor, is averaged from both experiments and interpreted as memory performance. $\boldsymbol{B}$, For modulation of shock number we varied the number of shocks applied during the training procedure. Shock impact was set to $15 \mathrm{~V}, 30 \mathrm{~V}, 60 \mathrm{~V}$, or $120 \mathrm{~V}$ DC. C, Performance of STM is plotted against the different combinations of shock number and impact used for training. Each bar represents the mean of $6-8$ biological repetitions. D, STM performance of $d n c^{1}$ mutants plotted against shock number as experienced during training sessions with 120 V DC. $\boldsymbol{E}$, STM performance of rut ${ }^{1}$ mutants plotted against shock iteration as experienced during training sessions with 120 V DC. $\boldsymbol{F}$, STM performance of wild-type Canton-S plotted against shock number as experienced during training sessions with $120 \mathrm{~V} D C$. Error bars indicate the mean \pm SEM $6-8$ biological repetitions, i.e., $N=6-8$. Statistical differences at level of $p \leq 0.05$ are denoted by different letters. Note that false colors are intended to improve clarity of each part and are not matched between parts.

ioral experiments were performed in dim red light at 70\% relative humidity with isoamyl acetate (1/100 dilution in mineral oil presented in a $14 \mathrm{~mm}$ cup) and ethyl acetate (1/200 dilution in mineral oil presented in a $14 \mathrm{~mm}$ cup) used as olfactory cues. The US was represented by DC pulses of $1.3 \mathrm{~s}$ duration; shock iteration and impact is indicated for each experiment.

For measuring performance of STM flies were tested immediately after the end of the training session; that is exactly 3 min after onset of training. Performance of MTM and ARM was determined at $3 \mathrm{~h}$ after training and flies were transferred to neutral containers without food for the resting period. For separation of consolidated ARM and labile ASM, two groups of flies were separately trained and one group was cooled in an ice bath $\left(0^{\circ} \mathrm{C}\right)$ for $90 \mathrm{~s}$ at $2.5 \mathrm{~h}$ after training and tested for odor memory after 30 min of recovery (cold + group). This treatment erases the labile ASM component thus performance of the cold + group is solely due to ARM. In contrast, ASM was calculated by subtracting the performance index of the cold + group (that performed due to ARM) from performance of the cold - group that performed due to ASM and ARM (Scheunemann et al., 2012). Calculation of behavioral indices was done as originally introduced by Tully and Quinn (1985).

Statistical analysis. All data were analyzed using IBM SPSS statistical package (Version 20.0). In case of wild-type we analyzed the effect of shock number and impact on STM, ARM, and MTM by use of two-way ANOVA with impact and number as main effects. In case of ASM we used three-way ANOVA with impact, number, and treatment (cold+ and cold-) as main effectors. Statistical differences were determined using LSD post hoc comparison. In case of experimental conditions using $120 \mathrm{~V}$ DC impact and variable numbers of shock we used two-way ANOVA for analysis of ASM with number and treatment (cold + and cold-) as main effectors; in case of ARM we used a one-way ANOVA with number set as effector. ASM values were calculated as the difference of the mean PI values of MTM and ARM. The error bars (SEM) of ASM were determined by adding the variances $\left(\sigma^{2}\right)$ of single PI values of MTM and ARM according to the following formula: $\operatorname{SEM}_{\mathrm{ASM}}=\left(\mathrm{V}\left[1 / N^{*} \sigma^{2}(\mathrm{MTM})+\right.\right.$ $\left.\left.\sigma^{2}(\mathrm{ARM})\right]\right)$.

\section{Results}

\section{STM is not an entity but composed of a basal and a}

\section{dynamic component}

Here, we modulated two parameters that contribute to reinforcement strength, i.e., the shock number, by varying the number of events experienced during a single-cycle training session (Fig.
$1 B$ ), and/or the impact by adjusting the overall intensity of the US to discrete values, i.e., $15 \mathrm{~V}, 30 \mathrm{~V}, 60 \mathrm{~V}$, or $120 \mathrm{~V} \mathrm{DC}$. As a result we received STM performance as a function of the two main effectors number and impact (Fig. 1C). Statistical analysis by use of two-way ANOVA revealed significant effects of impact $\left(F_{(4,146)}=\right.$ $35.48, p<0,01)$ and number $\left(F_{(4,146)}=45.21, p<0,01\right)$ as well as their interaction $\left(F_{(4,146)}=2.93, p<0,01\right)$. In line with this result post hoc analysis revealed that performance was correlated to shock number at high levels of impact, i.e., $120 \mathrm{~V} \mathrm{DC}\left(r_{(38)}=\right.$ $0.84, p<0.001)$, as well as to shock impact for frequent iterations, i.e., 12 reinforcing events $\left(r_{(330)}=0.65, p<0.001\right.$; Fig. $\left.1 C\right)$. As directly apparent from the false-colored image, acquisition of STM was degenerated as a particular level of performance could be reached by different combinations of shock number and impact, e.g., 50\% correct choice is achieved after being trained with either eight shock of $30 \mathrm{~V} \mathrm{DC}$, or alternatively with two shock of $120 \mathrm{~V}$ DC. This outcome is in line with the notion that STM is acquired in a graded fashion (Tully and Quinn, 1985), and shock number or impact seemed to be functionally compatible by means of performance. In contrast, no correlation was detected between STM performance and number at the $15 \mathrm{~V}$ DC impact level $\left(r_{(33)}=0.18, p=0.35\right)$ or between performance and impact when animals experienced only a single shock $\left(r_{(28)}=0.07, p=\right.$ $0.71)$. Despite the lack of significant performance increment, memory scores were in the range of $20-25 \%$, i.e., significantly different from a random distribution as revealed by one-way ANOVA $\left(F_{(8,48)}=8.92, p<0.01\right)$. This basal STM component, that is, immediately acquired after a single CS/US exposure at 15 V DC, is apparently different from the dynamic STM component that gradually increases proportional to shock iteration at sufficiently high impact levels. Thus, it appears that memory performance at $3 \mathrm{~min}$ is supported by two different components, a hypothesis that has already been proposed based on genetic evidence derived from the Drosophila learning mutants rutabaga ${ }^{1}$ $\left(r u t^{l}\right)$ and $d u n c e^{l}\left(d n c^{l}\right)$ affecting a type I $\mathrm{Ca}^{2+}$-sensitive adenylyl cyclase synthesizing cAMP (rut-AC1) and a cAMP-specific dunce phosphodiesterase hydrolyzing cAMP (Scheunemann et al., 2012). When we analyzed the effect of shock number at $120 \mathrm{~V} \mathrm{DC}$ 
impact level, we noticed that $d n c^{l}$ mutants-like wild-typeexhibited a significant correlation between number and performance $\left(r_{(32)}=0.76, p<0.001\right)$, while $r u t^{l} \operatorname{did} \operatorname{not}\left(r_{(17)}=-0.1\right.$, $p=0.58$; Fig. $1 D-F)$. This outcome formally separated acquisition mechanisms of basal and dynamic STM components in the genetic domain by means of their dynamics. Moreover, those mutants separate between consolidated ARM and labile ASM, two coexisting memory phases that support memory performance at $3 \mathrm{~h}$ after training and that differ with regard to withstand post-training amnestic cooling (Tempel et al., 1983; Knapek et al., 2011; Scheunemann et al., 2012).

\section{ASM formation is dually restricted by means of shock number and impact}

When we asked for the effect of shock number and/or impact on performance of either ARM or ASM separately, we disclosed a fundamental difference in the way those memory components are acquired (Fig. 2). First, we noted that acquisition of ARM appeared to be an instantaneous process without significant effects of treatment (Fig. $2 A$ ) as revealed by a two-way ANOVA testing for the impact of either shock number $\left(F_{(3,106)}=1.2, p=\right.$ $0.31)$, impact $\left(F_{(3,106)}=2.04, p=0.11\right)$, or their interaction $\left(F_{(3,106)}=0.45, p=0.90\right)$. In contrast, performance of MTM (Fig. $2 B$ ) was critically dependent on impact $\left(F_{(3,106)}=16.06, p<\right.$ $0.001)$ but not number $\left(F_{(3,106)}=1.97, p=0.13\right)$. Since MTM consists of consolidated ARM and labile ASM, we assumed this dependency to be a characteristic feature of ASM rather than ARM and hence, we calculated ASM performance (Fig. 2C) from two groups of animals that either received post-training amnestic treatment, or not (Knapek et al., 2011; Scheunemann et al., 2012). Statistical analysis was done by use of three-way ANOVA adding amnestic treatment as an additional main effector that exhibited a significant effect on performance $\left(F_{(3,106)}=197.90\right.$, $p<0.01)$, as did shock number $\left(F_{(3,106)}=3.81, p \leq 0.05\right)$, impact $\left(F_{(3,106)}=11.74, p<0.01\right)$ and the three-part interaction $\left(F_{(3,106)}=\right.$ $2.08, p \leq 0.05)$. Post hoc analysis revealed that interaction between shock number and ASM performance was restricted to impact levels of $120 \mathrm{~V} \mathrm{DC}(p<0.01)$, whereas performance of groups trained at $60 \mathrm{~V}, 30 \mathrm{~V}$, or $15 \mathrm{~V}$ DC impact showed no significant interaction $(p>0.50)$. At impact levels of $120 \mathrm{~V}$ DC two-way ANOVA exposed a significant effect of number $\left(F_{(3,106)}=11.74, p<0.01\right)$ and post hoc comparison identified a significant difference between the first and subsequent CS/US pairing $(p<0.01)$ but not between second and higher order pairing $(p>0.05)$. From this analysis we concluded that ASM was acquired via a two-step mechanism that was dually restricted to repeated and significant experience of an associative encounter.

\section{Dynamic features of two-step ASM formation}

From an analytical point of view the prominent two-step acquisition of ASM is highly advantageous and facilitated further determination of psychophysiological parameters critically affecting the acquisition of ASM. Therefore we adopted the training procedure to allow for delivery of short odor pulses (10 s) to access the implication of the intertrial intervals (ITI) in between two consecutive CS/US pairings (Fig. $3 A$, inlay). We discovered a significant effect of ITI length on ASM formation $\left(F_{(6,49)}=39.91\right.$, $p<0.01$ ) and post hoc analysis identified significant levels of performance for ITIs up to $300 \mathrm{~s}$ in between individual CS/US pairings ( $p \leq 0.05)$. The length of this time interval allowed us to experimentally test which of the two pairings required high level of shock impact (Fig. 3B). With the ITI remaining set to $60 \mathrm{~s}$ we permutated the $120 \mathrm{~V}$ DC impact level to either position of the
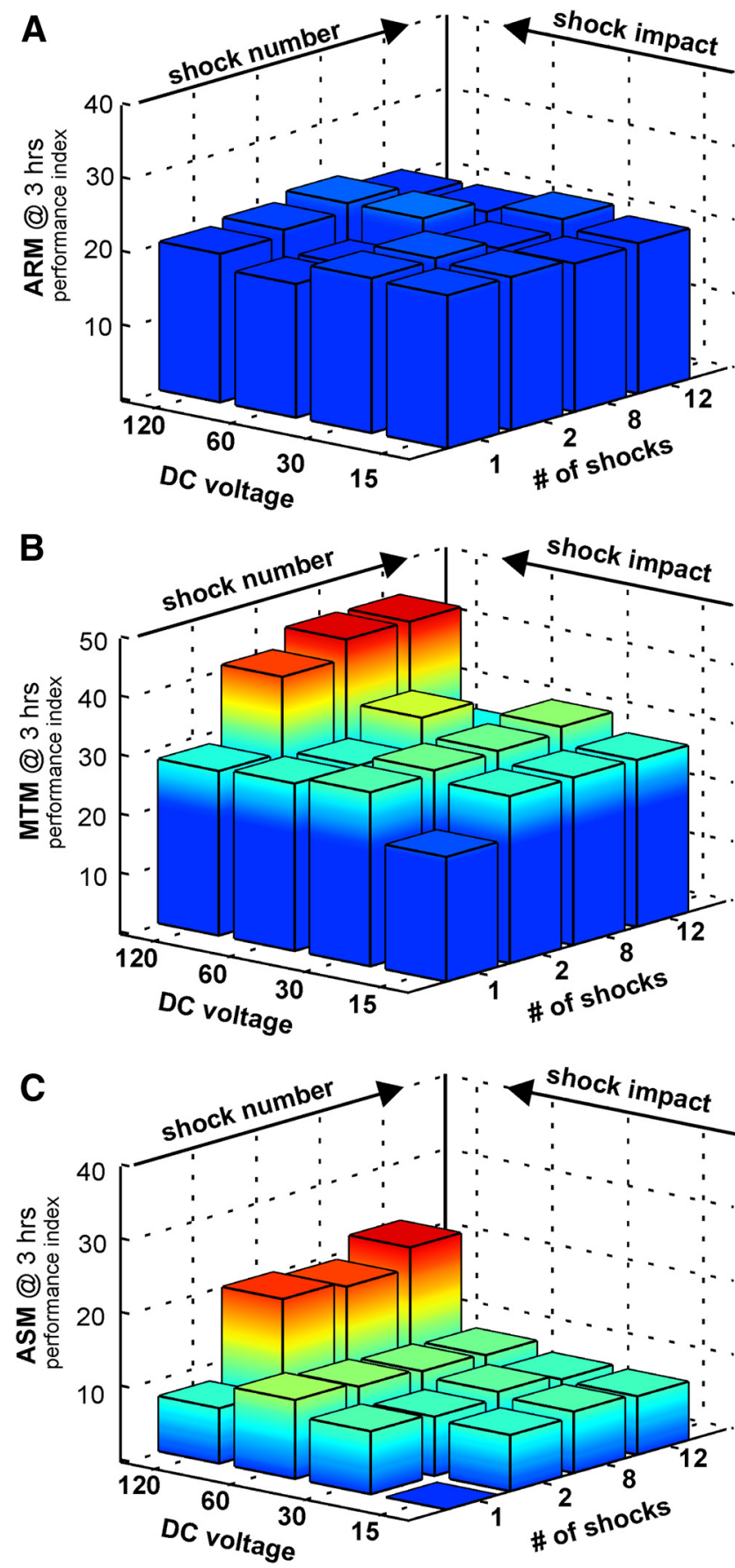

Figure 2. Distinct acquisition dynamics of consolidated and labile memories. At $3 \mathrm{~h}$ after training memory is proportionally supported by consolidated ARM and labile ASM. Shock impact and/or number differently affect those distinct memory phases. $A$, Performance of consolidated ARM is independent from variation of shock number and impact used for training. $\boldsymbol{B}$, Performance of labile ASM, in contrast, is doubly dependent on shock number and impact with repeated experience of high-impact reinforcement producing a characteristic "boost" in performance. $\boldsymbol{C}$, Performance of MTM, i.e., the composite of labile ASM and consolidated ARM, is plotted against the different combinations of shock number and impact used for training. $N=$ $6-8$ for each bar.

two trials and showed that high impact was critical at either position $\left(F_{(3,27)}=4.85 ; p<0,01\right)$. Finally, we tested for nonassociative learning components (Fig. $3 \mathrm{C}$ ) and did not detect significant levels of performance in nonassociative control groups $\left(F_{(4,28)}=4.38 ; p<0.01\right)$ suggesting that ASM forms due to associative learning. 

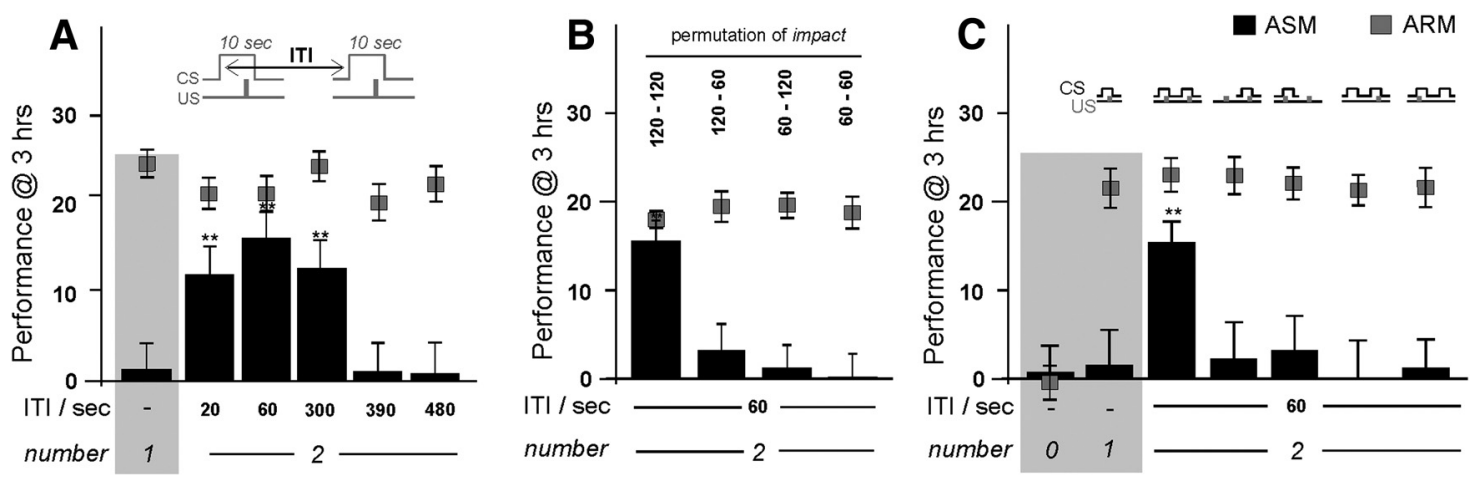

Figure 3. Psychophysical characterization of an ASM filter. Formation of ASM is critically dependent on two consecutive shock iterations administered in an associative context. To determine temporal aspects critical for this type of memory acquisition we modulated the training procedure to present short (10s) puffs of odor in combination with electric shock. Those CS/US pairings could be repeated at various ITIs (see inlay). Performance of ARM is indicated by gray symbols. A, Formation of ASM is dependent on a critical ITI in between two consecutive CS/US pairing that can last for up to 300 s. B, ASM formation requires an associative context, i.e., contingent presentation of CS and US, during either of the two conditioning trials. C, High shock impact, i.e., $>120 \mathrm{VDC}$, is required during either of the consecutive trials. Each error bar indicates the mean \pm SEM $6-8$ biological repetitions. Statistical differences at the level of $p \leq 0.05$ are denoted by different letters.

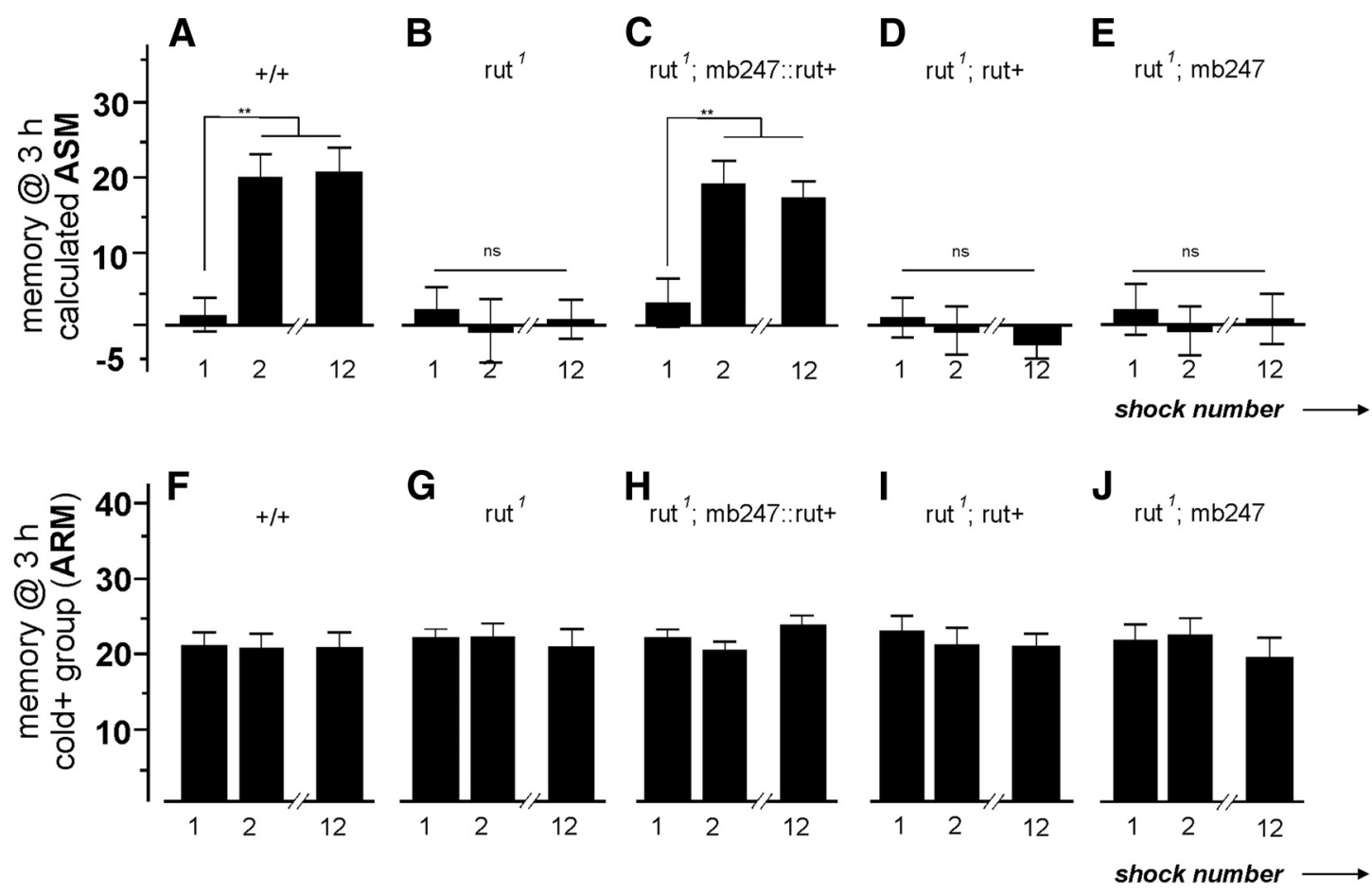

Figure 4. Rut-AC1 supports step-like ASM formation at the KC layer. Labile ASM and consolidated ARM are plotted against the increasing number of shockiterations experienced during training sessions with 120 V DC. A, Wild-type Canton-S shows characteristic stepwise acquisition of ASM. B, rut ${ }^{7}$ mutants do not form ASM. C, Genetic rescue of Rut-AC1 function within KCs marked in the mb247-Gal4 line is sufficient to restore two-step ASM formation. D,E, Genetic controls that bear either UAS-rut + or mb247-Gal4 in rut ' mutant background alone did not improve ASM. $\boldsymbol{F}$-J, Instantaneous formation of ARM is independent from rut ${ }^{7}$ mutant background. Error bars indicate the mean \pm SEM $6-8$ biological repetitions. Statistical differences at level of $p<0.01$ are denoted by asterisks $\left({ }^{* *}\right)$.

These experiments support several major conclusions: First, they suggest that ASM formation acts via an activated state that is induced during the first CS/US pairing and preserved within the brain for up to $300 \mathrm{~s}$. Such activated state, however, is behaviorally silent but absolutely necessary to complete two-step ASM acquisition by a consecutive pairing that must be experienced within that critical time window. Each of the two pairing is restricted to high shock impact resulting in the circumstance that formation of ASM is limited to extraordinary salient encounters. In this respect, formation of ASM dramatically differs from gradual formation of dynamic STM or the instantaneous acquisition of ARM and basal STM, resulting in a three-part dissociation of memory components by means of acquisition dynamics. To gain further insight into the neuronal and molecular organization of the ASM mechanism we focused on the rut learning mutant that is affecting a type I adenylyl cyclase previously shown to support ASM, but not the ARM component of $3 \mathrm{~h}$ memory (Scheunemann et al., 2012).

Two-step ASM formation requires protein kinase A (PKA)-Akinase anchoring proteins (AKAP) interactions in the Kenyon cell layer

Setting experimental conditions to high shock impact (120 V DC) we focused on shock numbers critical for two-step acquisition and monitored ASM performance (Fig. 4). While wild-type Canton-S (Fig. 4A) displayed characteristic two-step ASM formation rut $^{1}$ mutant animals (Fig. $4 B$ ) did not. Reintroducing wild-type rut + cDNA specifically at level of Kenyon cells (KCs) 

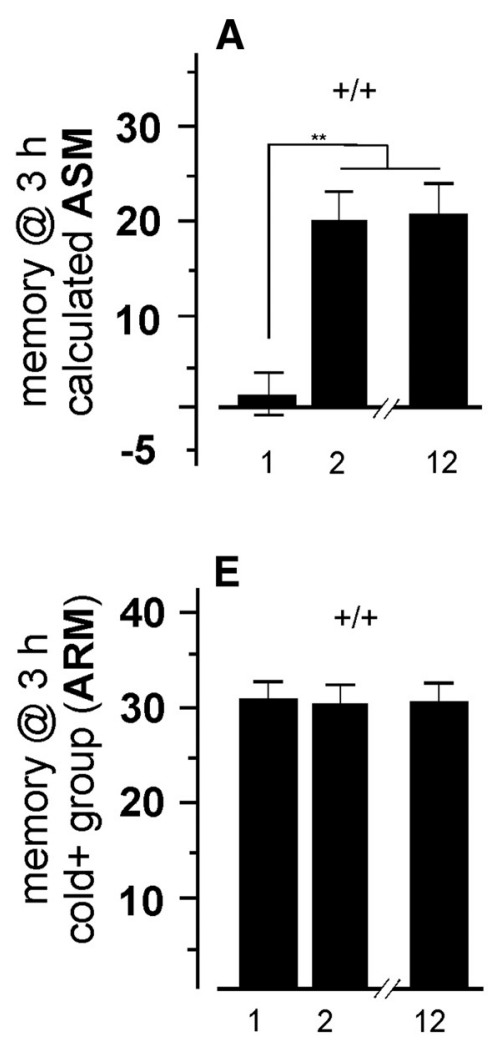

B

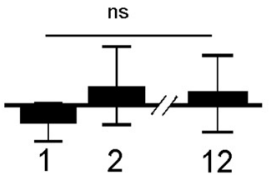

$\mathbf{F}$ mb247::ecopr2

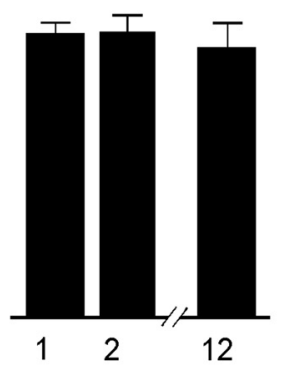

C mb247:ecopr2 $\Delta$

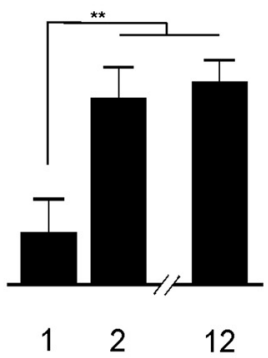

G mb247:ecopr2 $\Delta$

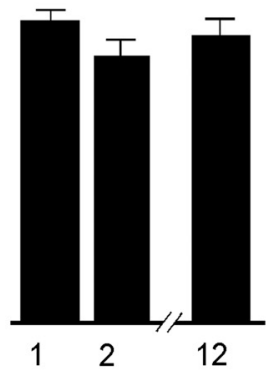

D

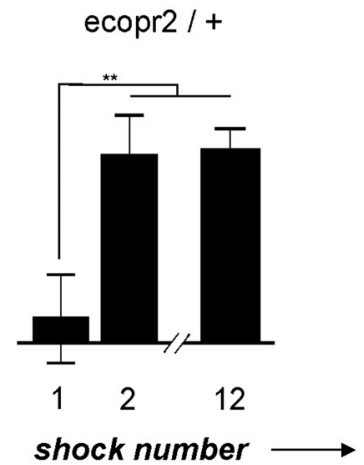

H ecopr2 /+

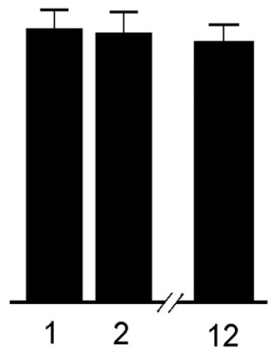

shock number

Figure 5. Step-like ASM formation requires AKAPs at the KC layer. Labile ASM and consolidated ARM are plotted against the increasing number of shock iterations experienced during training sessions with 120 V DC. $\boldsymbol{A}$, Wild-type Canton-S shows characteristic stepwise acquisition of ASM. $\boldsymbol{B}$, Expression of the ecopr2 peptide competitor that disrupts PKA-AKAP interaction prevents formation of ASM. Expression was restricted to KCs by use of the mb247-Gal4 line. C, D, Genetic controls that bear either ecopr2 or mb247-Gal4 alone did not affect ASM. $\boldsymbol{E}$ - $\boldsymbol{H}$, Instantaneous formation of ARM is unaffected in those genotypes. Error bars indicate mean \pm SEM $6-8$ biological repetitions. Statistical differences at level of $p<0.01$ are denoted by asterisks $\left({ }^{* *}\right)$.

within an otherwise rut $^{1}$ mutant brain (Fig. 4C) reinstalled twostep ASM formation $\left(F_{(2,17)}=10.17, p<0.01\right)$. Controls that bore any component of the Gal4/UAS system (Brand and Perrimon, 1993) alone, i.e., only the mb247-Gal4 element or the UASrut+ element alone in mutant background did not restore ASM (Fig. $4 D, E$ ). Importantly, neither the disruption of rut cyclase activity within rut $^{1}$ mutants, nor shock number exhibited significant effects on ARM performance (Fig. $4 F-J$ ). Thus, rut ${ }^{1}$ does not interfere with the instantaneous nature of ARM acquisition but appears to be restricted to dynamically acquired components, i.e., dynamic STM and ASM.

CAMP leads to activation of PKA which in turn can be tethered to defined cellular compartments by AKAPs (Skroblin et al., 2010). ASM performance is critically dependent on AKAP-PKA interactions, an interaction that is highly conserved at the molecular level and can be disrupted by use of the ecopr2-peptide inhibitor that resembles the AKAP binding domain of Drosophila PKA regulatory type II subunits (Schwaerzel et al., 2007). When we expressed the ecopr 2 inhibitor at level of KCs by use of mb247Gal4, characteristic two-step ASM acquisition immanent in wildtype (Fig. 5A) was abolished (Fig. 5B). In contrast, genetic controls that either expressed the impotent ecopr $2 \Delta$ control peptide (Schwaerzel et al., 2007) within the mb247-Gal4 pattern (Fig. $5 C$ ) or bore UAS-ecopr2 in the absence of the Gal4 transactivator (Fig. 5D) were not affected for ASM formation. Importantly, performance of ARM was independent from the presence of the ecopr 2 inhibitor (Fig. 5E-H) underpinning the strict dissociation of ASM and ASM acquisition in the molecular domain.

\section{Discussion}

Here, we established the benchmarking of Drosophila aversive odor memory performance by means of acquisition dynamics. We showed that different chronologies of CS/US pairings received throughout training correspond to the induction of distinct memory components. How do those dynamically defined components correspond to genetically defined components and what mechanistic insights can be derived from that analysis?

\section{A three-part composition of odor memory performance}

Conditioned odor avoidance is subject to a general dichotomy since multiple memory components are engaged in control of behavior. This is usually analyzed at two time points, i.e., $3 \mathrm{~min}$ and $3 \mathrm{~h}$ after training. At $3 \mathrm{~min}$, basal and dynamic STM are separable by genetic means as revealed by opposing phenotypes of $r u t^{1}$ and $d n c^{1}$ mutants. Moreover, those components are also separable due to characteristic differences in their acquisition dynamics as revealed by different effects of shock number. A similar dichotomy applied to $3 \mathrm{~h}$ memory when ASM and ARM were separable by means of amnestic treatment. It was striking that basal STM and consolidated ARM were instantaneously acquired, resulting in a front line of protection by eliciting conditioned avoidance after a singular experience of a CS/US pairing. Interestingly, consolidated ARM - as defined by means of resisting amnestic treatment-was installed quickly after training (Knapek et al., 2011). However, it remains to be addressed at the genetic and molecular level, whether $3 \mathrm{~h}$ ARM linearly results from the functionally similar basal SMT component. 
In contrast, the two components of dynamic STM and labile ASM acquire in a dynamic fashion but are clearly dissociated from each other by characteristic chronologies of CS/US pairings required for their acquisition. However, either component contributes to behavioral performance in addition to the appropriate instantaneous component, and hence, increases avoidance probability during the test situation. Considering a potential benefit from avoiding aversive situations this overall dichotomy of behavioral control seems plausible and is also reflected at the genetic level since rut-dependent cAMP signals are limited to support of dynamic but not instantaneous memory components. Rut-dependent STM and ASM, however, are dissociated by means of shock impact and discontinuous formation of ASM is limited to situations where animals repeatedly experience highimpact CS/US pairings within a predefined time window. Experience that does not meet this criterion, however, is not discounted but adds to continuously acquired dynamic STM. By functional means these two components are thus clearly separated but commonly dependent on rut-derived cAMP signals within the KC layer (Schwaerzel et al., 2002), forming ties between genetically and functionally defined memory components.

Genetic dissection of memory has a long-standing history in Drosophila and provided a powerful means to define molecular, cellular, and neuronal networks involved in regulation of conditioned odor avoidance (Yin et al., 1994; Isabel et al., 2004; Krashes et al., 2007; Blum et al., 2009; Gervasi et al., 2010; Chen et al., 2011; Knapek et al., 2011; Lee et al., 2011; Aso et al., 2012; Scheunemann et al., 2012). Among others, the cAMP-signaling cascade has been identified as one central tenet of aversive odor memory foremost by means of two single-gene mutants affecting either a $\mathrm{Ca}^{2+}$-sensitive type 1 adenylyl cyclase (AC1) and/or a cAMPspecific type 4 phosphodiesterase (PDE4) affected in the Drosophila learning mutants rutabaga (rut-AC1) and dunce (dnc-PDE4; Dudai et al., 1976; Livingstone et al., 1984). Although originally isolated due to poor performance in the aversive odor learning paradigm, we recently revealed a general dichotomy that separates memory components by their dependency on either rut-AC1 or dnc-PDE4 function and established the view that two different types of cAMP signals are engaged during the single-cycle training procedure (Scheunemann et al., 2012). A similar dichotomy is observed at level of acquisition dynamics and suggests that rut-dependent cAMP signals are limited to formation of dynamically acquired memory components, i.e., dynamic STM and ASM. Interestingly, rut-dependent cAMP is also required for long-term memory (LTM), which acquires after spaced and repeated training sessions (Blum et al., 2009). Downstream the signaling cascade, however, appropriate cAMP signals are differently channeled to either support LTM in a CREB-dependent manner (Tully et al., 1994; Yin et al., 1994), ASM via tomosyn-dependent plasticity (Chen et al., 2011), or basal STM via synapsin-dependent regulation of synaptic efficacy (Godenschwege et al., 2004; Knapek et al., 2010). It appears that the chronology of CS/US pairings is an important determinant of which downstream effect is triggered and hence molecular mechanisms must be installed that are sensitive to the temporal order of training.

\section{Do AKAPs provide register mechanisms that regulate memory formation?}

At the level of molecular scaffolds, literature suggests that AKAPs serve the integration of cAMP with other signaling processes and are crucially involved in the control of a plethora of cellular functions in any organ. For example, AKAP79 coordinates cAMP and
$\mathrm{Ca}^{2+}$ signaling in neurons to control ion channel activities (Dell'Acqua et al., 2006; Skroblin et al., 2010; Sanderson and Dell'Acqua, 2011). The recognized design principle of AKAPs to serve as molecular switch (Hoshi et al., 2003, 2005) is well in line with the recognized two-step register mechanism involved in ASM formation. An increasing body of evidence shows that AKAPs are involved in memory processing across phyla and accordantly those studies revealed a contribution for support of matured, but not immediate memories (Moita et al., 2002; Lu et al., 2007; Schwaerzel et al., 2007; Havekes et al., 2012). Communality among all those AKAP-dependent memories is the need for repeated and temporally organized training sessions, i.e., only spaced training sessions are effective to induce protein synthesisdependent LTM in flies and mammals (Tully et al., 2003; Havekes and Abel, 2009). Similarly, ASM requires the precise timing of two training sessions and mechanistically acts via an "activated" state generated by the initial CS/US pairing that persists within the brain for $\sim 5 \mathrm{~min}$. Such temporal integration might well take place at level of AKAPs within the KC layer to operate rut-AC1dependent cAMP signals finally onto phosphorylation of tomosyn. Identification of the particular AKAPs involved in two-step ASM formation will require further analysis of appropriate mutants. To date, only four Drosophila AKAPs are characterized, i.e., rugose, a $550 \mathrm{kDa}$ protein that impacts on STM performance probably via molecular domains other than its AKAP function (Volders et al., 2012); yu/spoonbill that supports LTM (Lu et al., 2007); and Nervy and AKAP $^{200}$ have not been tested for their impact on aversive odor memory.

Together, the benchmarking of Drosophila aversive odor memory performance by means of acquisition dynamics we installed here will provide a valuable tool since dynamic aspects of acquisition are obviously informative and add to the steady-state condition determined by the single-cycle training procedure.

\section{References}

Aso Y, Herb A, Ogueta M, Siwanowicz I, Templier T, Friedrich AB, Ito K, Scholz H, Tanimoto H (2012) Three dopamine pathways induce aversive odor memories with different stability. PLoS Genet 8:e1002768. CrossRef Medline

Blum AL, Li W, Cressy M, Dubnau J (2009) Short- and long-term memory in Drosophila require cAMP signaling in distinct neuron types. Curr Biol 19:1341-1350. CrossRef Medline

Brand AH, Perrimon N (1993) Targeted gene expression as a means of altering cell fates and generating dominant phenotypes. Development 118: 401-415. Medline

Chen K, Richlitzki A, Featherstone DE, Schwärzel M, Richmond JE (2011) Tomosyn-dependent regulation of synaptic transmission is required for a late phase of associative odor memory. Proc Natl Acad Sci U S A 108: 18482-18487. CrossRef Medline

Dell'Acqua ML, Smith KE, Gorski JA, Horne EA, Gibson ES, Gomez LL (2006) Regulation of neuronal PKA signaling through AKAP targeting dynamics. Eur J Cell Biol 85:627-633. CrossRef Medline

Dessauer CW (2009) Adenylyl cyclase-A-kinase anchoring protein complexes: the next dimension in cAMP signaling. Mol Pharmacol 76:935941. CrossRef Medline

Dudai Y, Jan YN, Byers D, Quinn WG, Benzer S (1976) dunce, a mutant of Drosophila deficient in learning. Proc Natl Acad Sci U S A 73:1684-1688. CrossRef Medline

Gervasi N, Tchénio P, Preat T (2010) PKA dynamics in a Drosophila learning center: coincidence detection by rutabaga adenylyl cyclase and spatial regulation by dunce phosphodiesterase. Neuron 65:516-529. CrossRef Medline

Godenschwege TA, Reisch D, Diegelmann S, Eberle K, Funk N, Heisenberg M, Hoppe V, Hoppe J, Klagges BR, Martin JR, Nikitina EA, Putz G, Reifegerste R, Reisch N, Rister J, Schaupp M, Scholz H, Schwärzel M, Werner U, Zars TD, et al. (2004) Flies lacking all synapsins are unexpect- 
edly healthy but are impaired in complex behaviour. Eur J Neurosci 20: 611-622. CrossRef Medline

Guo A, Li L, Xia SZ, Feng CH, Wolf R, Heisenberg M (1996) Conditioned visual flight orientation in Drosophila: dependence on age, practice, and diet. Learn Mem 3:49-59. CrossRef Medline

Havekes R, Abel T (2009) Genetic dissection of neural circuits and behavior in Mus musculus. Adv Genet 65:1-38. CrossRef Medline

Havekes R, Canton DA, Park AJ, Huang T, Nie T, Day JP, Guercio LA, Grimes Q, Luczak V, Gelman IH, Baillie GS, Scott JD, Abel T (2012) Gravin orchestrates protein kinase A and beta2-adrenergic receptor signaling critical for synaptic plasticity and memory. J Neurosci 32:18137-18149. CrossRef Medline

Hoshi N, Zhang JS, Omaki M, Takeuchi T, Yokoyama S, Wanaverbecq N, Langeberg LK, Yoneda Y, Scott JD, Brown DA, Higashida H (2003) AKAP150 signaling complex promotes suppression of the M-current by muscarinic agonists. Nat Neurosci 6:564-571. CrossRef Medline

Hoshi N, Langeberg LK, Scott JD (2005) Distinct enzyme combinations in AKAP signalling complexes permit functional diversity. Nat Cell Biol 7:1066-1073. CrossRef Medline

Isabel G, Pascual A, Preat T (2004) Exclusive consolidated memory phases in Drosophila. Science 304:1024-1027. CrossRef Medline

Knapek S, Gerber B, Tanimoto H (2010) Synapsin is selectively required for anesthesia-sensitive memory. Learn Mem 17:76-79. CrossRef Medline

Knapek S, Sigrist S, Tanimoto H (2011) Bruchpilot, a synaptic active zone protein for anesthesia-resistant memory. J Neurosci 31:3453-3458. CrossRef Medline

Krashes MJ, Keene AC, Leung B, Armstrong JD, Waddell S (2007) Sequential use of mushroom body neuron subsets during Drosophila odor memory processing. Neuron 53:103-115. CrossRef Medline

Lechner HA, Squire LR, Byrne JH (1999) 100 years of consolidation-remembering Muller and Pilzecker. Learn Mem 6:77-87. Medline

Lee PT, Lin HW, Chang YH, Fu TF, Dubnau J, Hirsh J, Lee T, Chiang AS (2011) Serotonin-mushroom body circuit modulating the formation of anesthesia-resistant memory in Drosophila. Proc Natl Acad Sci U S A 108:13794-13799. CrossRef Medline

Livingstone MS, Sziber PP, Quinn WG (1984) Loss of calcium/calmodulin responsiveness in adenylate cyclase of rutabaga, a Drosophila learning mutant. Cell 37:205-215. CrossRef Medline

Lu Y, Lu YS, Shuai Y, Feng C, Tully T, Xie Z, Zhong Y, Zhou HM (2007) The AKAP Yu is required for olfactory long-term memory formation in Drosophila. Proc Natl Acad Sci U S A 104:13792-13797. CrossRef Medline

McGaugh JL (2000) Memory-a century of consolidation. Science 287:248251. CrossRef Medline

McGuire SE, Deshazer M, Davis RL (2005) Thirty years of olfactory learning and memory research in Drosophila melanogaster. Prog Neurobiol 76: 328-347. CrossRef Medline
Moita MA, Lamprecht R, Nader K, LeDoux JE (2002) A-kinase anchoring proteins in amygdala are involved in auditory fear memory. Nat Neurosci 5:837-838. CrossRef Medline

Müller GE, Pilzecker A (1900) Experimentelle Beiträge zur Lehre von Gedächtnis. Zeitsch Psychol 1:1-300.

Sanderson JL, Dell'Acqua ML (2011) AKAP signaling complexes in regulation of excitatory synaptic plasticity. Neuroscientist 17:321-336. CrossRef Medline

Scheunemann L, Jost E, Richlitzki A, Day JP, Sebastian S, Thum AS, Efetova M, Davies SA, Schwärzel M (2012) Consolidated and labile odor memory are separately encoded within the Drosophila brain. J Neurosci 32: 17163-17171. CrossRef Medline

Schwaerzel M, Heisenberg M, Zars T (2002) Extinction antagonizes olfactory memory at the subcellular level. Neuron 35:951-960. CrossRef Medline

Schwaerzel M, Jaeckel A, Mueller U (2007) Signaling at A-kinase anchoring proteins organizes anesthesia-sensitive memory in Drosophila. J Neurosci 27:1229-1233. CrossRef Medline

Schwärzel M, Müller U (2006) Dynamic memory networks: dissecting molecular mechanisms underlying associative memory in the temporal domain. Cell Mol Life Sci 63:989-998. CrossRef Medline

Skroblin P, Grossmann S, Schäfer G, Rosenthal W, Klussmann E (2010) Mechanisms of protein kinase A anchoring. Int Rev Cell Mol Biol 283: 235-330. CrossRef Medline

Tempel BL, Bonini N, Dawson DR, Quinn WG (1983) Reward learning in normal and mutant Drosophila. Proc Natl Acad Sci U S A 80:1482-1486. CrossRef Medline

Tully T, Quinn WG (1985) Classical conditioning and retention in normal and mutant Drosophila melanogaster. J Comp Physiol A 157:263-277. CrossRef Medline

Tully T, Preat T, Boynton SC, Del Vecchio M (1994) Genetic dissection of consolidated memory in Drosophila. Cell 79:35-47. CrossRef Medline

Tully T, Bourtchouladze R, Scott R, Tallman J (2003) Targeting the CREB pathway for memory enhancers. Nat Rev Drug Discov 2:267-277. CrossRef Medline

Volders K, Scholz S, Slabbaert JR, Nagel AC, Verstreken P, Creemers JW, Callaerts P, Schwärzel M (2012) Drosophila rugose is a functional homolog of mammalian Neurobeachin and affects synaptic architecture, brain morphology, and associative learning. J Neurosci 32:15193-15204. CrossRef Medline

Yin JC, Wallach JS, Del Vecchio M, Wilder EL, Zhou H, Quinn WG, Tully T (1994) Induction of a dominant-negative CREB transgene specifically blocks long-term memory in Drosophila. Cell 79:49-58. CrossRef Medline 